NOTE

\title{
Conservation of the DNA sequences encoding the major structural viral proteins of WSSV
}

\author{
Zerong You ${ }^{1, *}$, E. Cesar B. Nadala Jr. ${ }^{3}$, Jinsheng Yang ${ }^{2}$, Philip C. Loh $^{1}$ \\ ${ }^{1}$ Department of Microbiology, and ${ }^{2}$ Department of Biochemistry, University of Hawaii, Honolulu, Hawaii 96822, USA \\ ${ }^{3}$ Department of Haematology, University of Cambridge, EABC Site, Long Road, Cambridge CB2 2PT, UK
}

\begin{abstract}
A cDNA library was constructed from white spot syndrome virus (WSSV)-infected penaeid shrimp tissue. cDNA clones with WSSV inserts were isolated and sequenced. By comparison with DNA sequences in GenBank, cDNA clones containing sequence identical to those of the WSSV envelope protein VP28 and nucleoprotein VP15 were identified. Poly(A) sites in the mRNAs of VP28 and VP15 were identified. Genes encoding the major viral structural proteins VP28, VP26, VP24, VP19 and VP15 of 5 WSSV isolates collected from different shrimp species and/or geographical areas were sequenced and compared with those of 4 other WSSV isolate sequences in GenBank. For each of the viral structural protein genes compared, the nucleotide sequences were 100 to $99 \%$ identical among the 9 isolates. Gene probes or PCR primers based on the gene sequences of the WSSV structural proteins can be used for diagnoses and/or detection of WSSV infection.
\end{abstract}

KEY WORDS: White spot syndrome virus $\cdot$ Viral structural proteins $\cdot$ VP28 $\cdot$ VP26 $\cdot$ VP24 $\cdot$ VP19 $\cdot$ VP15

Resale or republication not permitted without written consent of the publisher

\section{INTRODUCTION}

White spot syndrome virus (WSSV), which has been associated with major viral epizootics, was first identified in Taiwan and China between 1992 and 1993 (Chen 1995, Cai et al. 1995). WSSV has quickly spread to most shrimp-farming countries in Asia, such as Japan (Nakano et al. 1994), Thailand (Flegel et al. 1995), India (Mohan et al. 1998) and the Philippines (Magbanua et al. 2000). Although Asian in origin, WSSV was reported in the USA in 1995 in shrimp farms in Texas (Lightner et al. 1997) and subsequently in South Carolina (Nadala \& Loh 1998). Since January 1999, WSSV has been detected in tissue samples of cultured shrimp from Central and South America (www.aphis.usda.gov/vs/aqua/wssv.html). In addition to cultured penaeid shrimp, WSSV has been detected in other crustaceans, including crabs and crayfish (Lo et al. 1996). The genomes of $3 \mathrm{WSSV}$ isolates have been sequenced (Lo \& Kou 2001, van Hulten et al.

*Email: zerong@hawaii.edu
2001, Yang et al. 2001), providing a molecular basis for proper classification and better understanding of WSSV replication and pathogenicity. Previous studies have shown that genetic variations exist among WSSV isolates (Nadala \& Loh 1998, Lo et al. 1999). In this study, cDNA clones containing the genes encoding the WSSV envelope protein VP28 and nucleoprotein VP15 were isolated and the poly(A) sites in the mRNAs were identified. The genes encoding the major structural proteins of WSSV isolated from different geographic areas and from different shrimp species were sequenced and compared.

\section{MATERIALS AND METHODS}

WSSV 95C, previously named Chinese baculovirus (CBV), was originally isolated from Penaeus japonicus from Dalian, China (Lu et al. 1997). A cDNA library was constructed from WSSV 95C-infected shrimp tissue as

(C) Inter-Research $2004 \cdot$ www.int-res.com 
Table 1. WSSV isolates from which structural protein genes were compared in this study

\begin{tabular}{|llll|}
\hline Viral isolate & Origin & Host animal & Source \\
\hline WSSV 95C $^{\mathrm{a}}$ & Dalian, China & Penaeus japonicus & This study \\
WSSV 97Indo & Indonesia & Penaeus monodon & This study \\
WSSV 98Japan & Japan & Penaeus japonicus & This study \\
WSSV 98SCa & South Carolina, USA & Penaeus setiferus & This study \\
WSSV 99C & Qingdao, China & Penaeus chinesis & This study \\
WSSV Xiamen & Xiamen, China & Penaeus japonicus & Yang et al. (2001) \\
WSSV Thailand & Thailand & Penaeus monodon & van Hulten et al. (2001) \\
WSSV Taiwan & Taiwan & Not specified & Lo \& Kou (2001) \\
WSSV Korea & Korea & Penaeus chinesis & Moon et al. (2003) \\
${ }^{\text {a }}$ The structural protein genes (vp15, 19, 24, 26 and 28) of these isolates were sequenced in this study. The nucleotide \\
sequences were deposited in GenBank (accession numbers: AY249434 to AY249458)
\end{tabular}

follows. Total RNA was isolated from WSSV 95Cinfected shrimp gill tissues using $\mathrm{TRL}_{\mathrm{ZOL}}{ }^{\circledR} \mathrm{LS}$ Reagent (GIBCO). The mRNAs were isolated from the total RNA using Oligotex ${ }^{\mathrm{TM}}$ (Qiagen). cDNA was synthesized using the TimeSaver ${ }^{\mathrm{TM}}$ cDNA Synthesis Kit (Amersham Pharmacia Biotech) with Oligo(dT) ${ }_{12-18}$ as primer. The cDNA library was constructed by cloning cDNA into ECoRI-digested plasmid vector pUC19 and using this to transform competent E. coli XL1-Blue cells. WSSV 95C genomic DNA was isolated as previously described (You et al. 2002) and labeled with digoxigenin (DIG)dUTP (Boehringer Mannheim). The WSSV-cDNA clones were selected from the cDNA library by hybridization with the DIG-labeled WSSV genomic DNA probe. DNA sequencing was performed with an automated DNA sequencer (Model 377, Applied Biosystems) at the Biotechnology and Molecular Biology Instrumentation Facilities, University of Hawaii.

Five WSSV isolates were used in this study (Table 1). Specific pathogen-free (SPF) Penaeus vannamei were used for WSSV propagation. WSSV propagation and purification methods have been described by Nadala et al. (1998).

For sequence comparison of the genes encoding the major structural proteins of WSSV isolated from different shrimp species and/or geographic areas, 5 pairs of primers (Table 2) were designed, based on the DNA sequences of VP28, 26, 24,19 and 15 of the WSSV Thailand isolate (van Hulten et al. 2001). Genomic DNA of 5 WSSV isolates (Table 1) was purified as described previously (You et al. 2002). The PCR reactions were performed using the GeneAmp PCR System 9600 (Perkin Elmer). Standard PCR reactions (final volume of $50 \mu \mathrm{l}$ ) contained $10 \mathrm{ng}$ of WSSV DNA, $200 \mu \mathrm{M}$ each of dATP, dTTP, dCTP and dGTP, $0.2 \mu \mathrm{M}$ of each specific primer, $2.5 \mathrm{mM} \mathrm{MgCl}_{2}$ and 1.25 units Pfu DNA polymerase (Stratagene). The PCR was run for 30 cycles of $30 \mathrm{~s}$ at $94^{\circ} \mathrm{C}, 30 \mathrm{~s}$ at $60^{\circ} \mathrm{C}$ and $30 \mathrm{~s}$ at $72^{\circ} \mathrm{C}$. The PCR products were purified using a PCR purification kit (Qiagen) and sequenced in both directions.

cDNA sequences were analyzed using the BLAST ${ }^{\circledR}$ program. Homologous sequences were aligned using ClustalW (Thompson et al. 1994) (clustalw.genome. ad.jp) and the alignments were printed out with the BOXSHADE program (bioweb.pasteur.fr/seqanal/ interfaces/boxshade.html).

\section{RESULTS AND DISCUSSION}

Among the WSSV cDNA clones which were identified and sequenced, clone 95C-C6 had an insert of $\sim 750$ base pairs (bp). An open reading frame (ORF) of $615 \mathrm{bp}$ was identified in this insert. Nucleic acid

Table 2. Primers used for PCR and sequencing of genes encoding the WSSV major structural proteins

\begin{tabular}{|ccc|}
\hline Gene & \multicolumn{1}{c}{ Primers } & $\begin{array}{c}\text { Size of PCR } \\
\text { product (bp) }\end{array}$ \\
\hline vp28 & $\begin{array}{l}\text { vp28F 5' CGACATCTTAATAACCAAGCAACG 3' } \\
\text { vp28R 5' AAAAGCACGATTTATTTACTCGG 3' }\end{array}$ & 677 \\
vp26 & $\begin{array}{l}\text { vp26F 5' ATCCAACCAACACGTAAAGG 3' } \\
\text { vp24 }\end{array}$ & 673 \\
& vp26R 5' CAATTCCCACTTTACTTCTTCTTG 3' & \multirow{2}{*}{ vp24F 5' AATAAATCTCTCCCTAACAATGAAAGG 3' } \\
vp19 & $\begin{array}{l}\text { vp24R 5' TTTTCTCTCATGACCTTTGTACAACTT 3' } \\
\text { vp19F 5' GTCTTTACGTTACATTGACGTAC 3' }\end{array}$ & \multirow{2}{*}{466} \\
vp15 & $\begin{array}{l}\text { vp19R 5' GTTTTAATTATAATTTTTGTCC 3' } \\
\text { vp15F 5' CTTAACCACAGTTGCACTCAC 3' }\end{array}$ & \multirow{2}{*}{468} \\
& vp15R 5' GTACCCTTAAACTTTTATACCAC 3' & \\
\hline
\end{tabular}


sequence comparison showed that the ORF was identical to that of ORF1 from the WSSV Thailand isolate (van Hulten et al. 2001), which encodes an envelope protein VP28 (van Hulten et al. 2000). VP28 is equivalent to the envelope protein VP27.5 identified previously from CBV (Nadala et al. 1998). The ORF in clone 95C-C6 was identical to the following WSSV DNA sequences in GenBank: ORF wssv480 of the WSSV Taiwan isolate (Lo \& Kou 2001) and ORF wsv421 of the WSSV Xiamen isolate, China (Yang et al. 2001). A putative poly(A) signal AATAAA was found $54 \mathrm{bp}$ downstream of the ORF stop codon TAA in the WSSV
cDNA insert in clone 95C-C6. The poly(A) tail was $15 \mathrm{bp}$ downstream of the poly(A) signal (Fig. 1). The position of the poly $(\mathrm{A})$ site was confirmed by sequencing another cDNA clone, 95C-C8, which has an insert containing vp28 gene sequences and a poly(A) tail.

Zhang et al. (2002) isolated a cDNA clone C37 from a cDNA library of WSSV-infected Penaeus japonicus tissue from Xiamen, China. Clone C37 was found to contain the gene encoding the VP28 protein. Two putative poly(A) signals (54 and $201 \mathrm{bp}$ downstream of the vp28 gene stop codon, respectively) and a poly(A) site (221 bp downstream of the vp28 gene stop codon)

\begin{tabular}{|c|c|}
\hline ORF1 & TAAATAAATCGTGCTTTTTTATATAGATAGGGAATTTTAATATTACAACAATAAGAAAATAAAACAATTG \\
\hline WSSV 480 & TAAATAAATCGTGCTTTTTTATATAGATAGGGAATTTTAATATTACAACAATAAGAAAATAAAACAATTG \\
\hline WSV421 & TAAATAAATCGTGCTTTTTTATATAGATAGGGAATTTTAATATTACAACAATAAGAAAATAAAACAATTG \\
\hline C37 & TAAATAAATCGTGCTTTTTTATATAGATAGGGAATTTTAATATTACAACAATAAGAAAATAAAACAATTG \\
\hline $95 \mathrm{C}-\mathrm{C} 6$ & $\begin{array}{l}\text { TAAATAAATCGTGCTTTTTTATATAGATAGGGAATTTTAATATTACAACAATAAGAAAATAAAACAATTG } \\
1 \ldots \ldots \ldots 10 \ldots \ldots \ldots \\
\text { Stop codon of vp } 28 \text { gene }\end{array}$ \\
\hline
\end{tabular}

ORF1

WSSV 480

WSV 421

C37

$95 \mathrm{C}-\mathrm{C} 6$

ORF1

WSSV 480

wSV 421

C37

ORF1

WSSV 480

WSV 421

C37

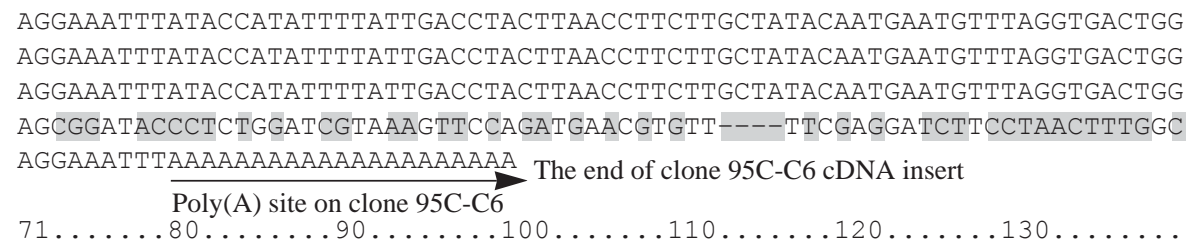

AAAAGTTTAGCAATATTATCCTTGAACGGGAAACATGCACCAATTACAGGCGCAATTTCATACGCTCTCG AAAAGTTTAGCAATATTATCCTTGAACGGGAAACATGCACCAATTACAGGCGCAATTTCATACGCTCTCG AAAAGTTTAGCAATATTATCCTTGAACGGGAAACATGCACCAATTACAGGCGCAATTTCATACGCTCTCG CACATCCAAGTAAAGGTCTTCAATCACGGTGAACACATCCGCCATAATTAGGTAATACCGTTATATCAGA

$141 \ldots \ldots 150 \ldots \ldots 160 \ldots \ldots 170 \ldots \ldots 180 \ldots \ldots 190 \ldots \ldots 200 \ldots \ldots$

GCCTATTGGTCTTTTCCTGGTCATACATTTTAGATACAATAGACAAAAATGGAATGTTTGTATAGATAGA GCCTATTGGTCTTTTCCTGGTCATACATTTTAGATACAATAGACAAAAATGGAATGTTTGTATAGATAGA GCCTATTGGTCTTTTCCTGGTCATACATTTTAGATACAATAGACAAAAATGGAATGTTTGTATAGATAGA CACTGGTTATGATTGCCATTTTAGAGTCTGACCATTAATTCCGAGCAAAAGAAATA---AAATTAAAAAA

Second poly(A)signal

$211 \ldots \ldots 220 \ldots \ldots 230 \ldots 240 \ldots 250 \ldots 260 \ldots 270 \ldots$

$\begin{array}{ll}\text { ORF1 } & \text { ATTGGCAG } \\ \text { WSSV480 } & \text { ATTGGCAG } \\ \text { WSV421 } & \text { ATTGGCAG } \\ \text { C37 } & \text { ATTGAC } \underset{\text { Poly(A) site on mRNA on clone C37 }}{\longrightarrow} \\ & 281 \ldots\end{array}$

Fig. 1. Boxshade of multiple-aligned WSSV genomic DNA and mRNA (cDNA) sequences, starting from the stop codon (TAA) of the gene encoding the VP28 kDa protein. ORF1: DNA sequence of the WSSV Thailand isolate (van Hulten et al. 2001, GenBank accession no. AF369029: from 613 to 900 bp). wssv480: DNA sequence of the WSSV Taiwan isolate (Lo \& Kou 2001, GenBank accession no. AF440570: from 279477 to 279764 bp). wsv421: DNA sequence of the WSSV Xiamen isolate (Yang et al. 2001, GenBank accession no. AF332093: from 244854 to 245141 bp). C37: mRNA sequence (clone C37) of the WSSV Xiamen isolate (Zhang et al. 2002, GenBank accession no. AF227911: from 1095 to 1373 bp). 95C-C6: cDNA clone sequence of WSSV95C (this study, GenBank accession no. AY249434). Grey shading shows the differences between the C37 insert sequence (mRNA) and the corresponding genomic DNA sequence of the WSSV Xiamen isolate and the other isolates 
were identified in the insert of clone C37 by Zhang et al. (2002). However, we analyzed the genome sequence of WSSV isolated from infected $P$. japonicus tissue from Xiamen, China (Yang et al. 2001) and found only one putative poly(A) signal (54 bp downstream of the vp28 gene stop codon) for the vp28 gene (ORF wsv421) (Fig. 1). Analysis of the genomic sequence downstream of vp28 genes of WSSV from Thailand (van Hulten et al. 2001) and Taiwan (Lo \& Kou 2001) also showed only one putative poly(A) signal, which is consistent with our sequencing results. Further study is needed to find out why the second poly(A) signal in clone C37 is not present in the WSSV genome. We have also noted that the 3 '-nontranslated region of the vp28 mRNA (C37) reported by Zhang et al. (2002) showed significant base changes when compared to its genomic counterpart in the WSSV isolate from Xiamen, China (Yang et al. 2001) and 2 other WSSV isolates (Lo \& Kou 2001, van Hulten et al. 2001) (Fig. 1). Generally, precursor RNAs made in the nuclei of eukaryotic cells undergo 3 types of modification. These include methylation of the 2 '-hydroxyl group of the ribose near the co-transcriptionally added cap, removal of introns and polyadenylation before transport into the cytoplasm for translation. Many genes have been characterized as having alternative polyadenylation sites at the 3 '-end of their mRNAs, according to the cellular environment. Multiple poly(A) sites have been observed in the genes of herpes simplex virus and adenovirus. Apart from the observations of Zhang et al. (2002), significant base alterations in the 3 '-nontranslated region have not been reported.

Another WSSV cDNA clone, 95C-C958, had a 313 bp insert (GenBank accession no. AY245783). The ORF in the cDNA insert encoded a 61 amino acid peptide, which was identical to the peptide sequence of the WSSV structural protein VP15 (van Hulten et al. 2002) and WSSV basic peptide P6.8 (Zhang et al. 2001). A poly(A) site was found $15 \mathrm{bp}$ downstream of a putative poly(A) signal (AATAAA), which was consistent with the finding of Zhang et al. (2001).

In this study, genes encoding 5 viral structural proteins (VP15, 19, 24, 26 and 28) of 5 different geographical WSSV isolates (Table 1) were sequenced. Sequence comparison indicated that, as in 4 other WSSV isolates reported (Table 1), the sequences of each gene were all identical among the 9 isolates (Table 1). The only exception was the vp28 gene of the Korean isolate which has 1 base difference from that of other WSSV isolates, but this alteration does not cause a change in the amino acid sequence (Moon et al. 2003). These results strongly suggest that the genes of WSSV structural proteins are highly conserved.

Though highly conserved, variations have been observed in WSSV structural protein sequences. Wang et al. (2000) sequenced the $\mathrm{NH}_{2}$-terminal sequence of a $14.5 \mathrm{kDa}$ nucleocore protein of WSSV isolated from Litopenaeus setiferus from South Carolina, USA, in 1998 as VARGGKTKGRRG (Swiss-Prot Protein Data Bank accession no. P82006). Assuming the $14.5 \mathrm{kDa}$ protein is equivalent to the VP15 protein, it is only $74 \%$ identical to this protein (VARSSKTKSRRG) in the other 8 WSSV isolates. Wang et al. (2000) also showed that the $19 \mathrm{kDa}$ envelope protein of WSSV isolated from crayfish appeared slightly larger in size than that of WSSV isolated from shrimp. Protein sequencing is needed to confirm this difference.

The conservation of the DNA and amino acid sequences of the structural proteins of different WSSV isolates provides the molecular basis for the development of highly specific and sensitive nucleic acid and immuno-based detection methodologies for WSSV. For example, polyclonal antibodies developed against the complete virion (Nadala et al. 1997, 1998) or the immuno-dominant structural protein VP27.5 (You et al. 2002) have been successfully employed in the detection of different geographical WSSV isolates by Western blot (Nadala et al. 1997, Magbanua et al. 2000) and immuno-dot procedures (Nadala \& Loh 2000). Furthermore, as shown in the present study, PCR primers prepared from the gene sequence of the structural viral proteins can be used for WSSV diagnosis/ detection. However, it is epidemiologically important to be able to distinguish the different geographical isolates of WSSV. Studies have shown that in hosts such as Litopenaeus vannamei and Farfantepenaeus duorarum, the WSSV isolated from different geographical areas can show variation in virulence (Wang et al. 1999). Although restriction fragment length polymorphism (RFLP) and genomic sequence analyses may show differences, more studies are needed to identify other genetic markers which could also help to track the WSSV involved in an outbreak.

Acknowledgements. This study was supported by grants from the University of Hawaii Sea Grant and College Program, Institutional Grant No. R/AQ-46 and the University of Hawaii Education Improvement Fund.

\section{LITERATURE CITED}

Cai SL, Huang J, Wang CM, Song XL, Sun X, Yu J, Zhang Y, Yang CH (1995) Epidemiological studies on the explosive epidemic disease of prawn in 1993-1994. J China Fish 19: 112-117

Chen SN (1995) Current status of shrimp aquaculture in Taiwan. In: Browdy CL, Hopkins JS (eds) Swimming through troubled water. Proc Spec Sess Shrimp Farming. Aquaculture'95. World Aquaculture Society, Baton Rouge, LA, p 29-34

Flegel TW, Fegan DF, Sriurairatana S (1995) Environmental control of infectious disease in Thailand. In: Browdy CL, 
Hopkins JS (eds) Swimming through troubled water. Proc Spec Sess Shrimp Farming, Aquaculture'95. World Aquaculture Society, Baton Rouge, LA, p 65-79

Lightner DV, Redman RM, Poulos BT, Nunan LM, Mari JL, Hasson KW (1997) Risk of spread of penaeid shrimp viruses in the Americas by the international movement of live shrimp for aquaculture and frozen shrimp for commodity market. Rev Sci Techn Off Int Epizoot 16:146-160

Lo CF, Kou GH (2001) Shrimp white spot syndrome virus complete genome sequence. GenBank accession no. AF440570

Lo CF, Ho CH, Peng SE, Chen CH and 7 others (1996) White spot syndrome baculovirus (WSBV) detected in cultured shrimp, crabs and other arthropods. Dis Aquat Org 27: 215-225

Lo CF, Hsu HC, Tsai MF, Ho CH, Peng SE, Kou GH, Lightner DV (1999) Specific genomic DNA fragment analysis of different geographical clinical samples of shrimp white spot syndrome virus. Dis Aquat Org 35:175-185

Lu Y, Tapay LM, Loh PC, Gose RB, Brock JA (1997) The pathogenicity of a baculo-like virus isolated from diseased penaeid shrimp obtained from China for cultured penaeid species in Hawaii. Aquac Int 5:277-282

Magbanua FO, Natividad KT, Migo VP, Alfafara CG and 6 others (2000) White spot syndrome virus (WSSV) in cultured Penaeus monodon in the Philippines. Dis Aquat Org 42:77-82

Mohan CV, Shankar KM, Kulkarni S, Sudha PM (1998) Histopathology of cultured shrimp showing gross signs of yellow head syndrome and white spot syndrome during 1994 Indian epizootics. Dis Aquat Org 34:9-12

Moon CH, Do JW, Cha SJ, Yoon WJ and 7 others (2003) Highly conserved sequences of three major virion proteins of a Korean isolate of white spot syndrome virus (WSSV). Dis Aquat Org 53:11-13

Nadala EC Jr, Loh PC (1998) A comparative study of three different isolates of white spot virus. Dis Aquat Org 33: 231-234

Nadala EC Jr, Loh PC (2000) Dot-blot nitrocellulose enzyme immunoassays for the detection of white-spot virus and yellow-head virus of penaeid shrimp. J Virol Methods 84: 175-179

Nadala EC Jr, Tapay LM, Cao S, Loh PC (1997) Detection of yellow head virus and Chinese baculovirus in penaeid shrimp by the Western blot technique. J Virol Methods 69: $39-44$

Editorial responsibility: Timothy Flegel,

Bangkok, Thailand
Nadala EC Jr, Tapay LM, Loh PC (1998) Characterization of a non-occluded baculovirus-like agent pathogenic to penaeid shrimp. Dis Aquat Org 33:221-229

Nakano H, Koube H, Umezawa S, Momoyama K, Hiraoka M, Inouye K, Oseko N (1994) Mass mortalities of cultured Kuruma shrimp, Penaeus japonicus in Japan in 1993. Fish Path 29:135-139

Thompson JD, Higgins D, Gibson TJ (1994) CLUSTAL W: improving the sensitivity of progressive multiple sequence alignment through sequence weighting, position-specific gap penalties and weight matrix choice. Nucleic Acids Res 22:4673-4680

van Hulten MC, Westenberg M, Goodall SD, Vlak JM (2000) Identification of two major virion protein genes of white spot syndrome virus of shrimp. Virology 266: 227-36

van Hulten MC, Witteveldt J, Peters S, Kloosterboer N and 5 others (2001) The white spot syndrome virus DNA genome sequence. Virology 286:7-22

van Hulten MC, Reijns M, Vermeesch AM, Zandbergen $F_{1}$ Vlak JM (2002) Identification of VP19 and VP15 of white spot syndrome virus (WSSV) and glycosylation status of the WSSV major structural proteins. J Gen Virol 83: 257-265

Wang Q, White BL, Redman RM, Lightner DV (1999) Per os challenge of Litopenaeus vannamei postlarvae and Farfantepenaeus duorarum juveniles with six geographic isolates of white spot syndrome virus. Aquaculture 170: 179-194

Wang Q, Poulos BT, Lightner DV (2000) Protein analysis of geographic isolates of shrimp white spot syndrome virus. Arch Virol 145:263-274

Yang F, He J, Lin X, Li Q, Pan D, Zhang X, Xu X (2001) Complete genome sequence of the shrimp white spot bacilliform virus. J Virol 75:11811-11820

You Z, Nadala C, Yang J, van Hulten MC, Loh PC (2002) Production of polyclonal antiserum specific to the $27.5 \mathrm{kDa}$ envelope protein of white spot syndrome virus. Dis Aquat Org 51:77-80

Zhang X, Xu X, Hew CL (2001) The structure and function of a gene encoding a basic peptide from prawn white spot syndrome virus. Virus Res 79:137-144

Zhang X, Huang C, Xu X, Hew CL (2002) Identification and localization of a prawn white spot syndrome virus gene that encodes an envelope protein. J Gen Virol 83: 1069-1074

Submitted: March 24, 2003; Accepted: July 6, 2004 Proofs received from author(s): September 28, 2004 